\title{
No reclame da liberdade: as lutas antimanicomiais dos anos 1990 pelos seus cartazes de divulgação
}

| ${ }^{1}$ Wanda Espírito Santo, ${ }^{2}$ Inesita Araújo |

Resumo: O artigo objetiva compreender como as vozes que têm transformado as práticas e as concepçôes sobre a loucura organizaram seu discurso e disputaram sentidos nos espaços públicos, através da análise de materiais de divulgação do Movimento da Reforma Psiquiátrica no Brasil. Mais especificamente, de cartazes da década de 1990, um dos momentos sócio-históricos discursivos estudados na tese "Movimentos Sociais em Saúde e Estratégias de Produção de Sentidos: no reclame da liberdade, o novo lugar da loucura”. Os cartazes foram analisados em seus discursos, procurando identificar, compreender e comparar os dispositivos de enunciação do material avaliado, tendo como contraponto sua dimensão temporal e geográfica. Os resultados mostram que os anos 1990 como um tempo de consolidação do movimento e das práticas antimanicomiais, sendo cultura, liberdade e cidadania os principais valores em torno dos quais se articulou a produção de sentidos naquele momento histórico.

> Palavras-chave: comunicação e saúde; luta antimanicomial; análise social de discursos.
${ }^{1}$ ICICT, Fundação Oswaldo Cruz. Rio de Janeiro-RJ, Brasil (wandaes@gmail.com). ORCID 0000-0003-1724-2033

${ }^{2}$ ICICT, Fundação Oswaldo Cruz. Rio de Janeiro-RJ, Brasil (inesitaaraujo@gmail.com). ORCID: 0000-0001-6927-5430

Recebido em: 12/09/2017 Revisado em: 11/02/2019 Aprovado em: 15/02/2019 


\section{Contextos}

Desenvolvemos uma pesquisa de tese de doutorado sobre os materiais de divulgação do Movimento Nacional de Luta Antimanicomial, mais especificamente os cartazes comemorativos do Dia Nacional de Luta Antimanicomial. Para este fim, selecionamos materiais produzidos de 1978 a 2013. O objetivo principal foi compreender como as vozes que têm transformado as práticas e as concepçôes sobre a loucura organizam seu discurso e disputam sentidos no espaço público, e a tese foi defendida em 2015, no Programa de Pós-graduação em Informação e Comunicação em Saúde (Icict/Fiocruz), com o título "Movimentos Sociais em Saúde e Estratégias de Produção de Sentidos: no reclame da liberdade, o novo lugar da loucura".

Nossa pesquisa inclui cartazes que circularam a partir da década de 1970, época em que ocorreram graves denúncias contra o sistema nacional de assistência psiquiátrica. O propósito foi o de compreender mudanças na produção de sentidos ocorridas a partir do II Congresso de Trabalhadores de Saúde Mental, realizado na cidade de Bauru, São Paulo, em 1987, marco histórico no qual teve início o Movimento Nacional de Luta Antimanicomial. Fazemos especificamente a análise de cartazes da década de 1990, escolhendo os de 1997 por marcar a comemoração dos dez anos desse encontro. Com base nos enunciados dos cartazes, em específico buscamos compreender como as vozes que têm transformado as práticas e as concepções sobre a loucura organizaram seu discurso e disputaram sentidos no espaço em um dos momentos sócio-históricos discursivos estudados na tese.

No Brasil, o Movimento da Reforma Psiquiátrica surgiu na década de 1970, durante o regime militar, de 1964 até 1985. O Movimento de Trabalhadores em Saúde Mental (MTSM) surgiu em 1978, a partir de graves denúncias contra o sistema nacional de assistência psiquiátrica, acusaçôes acompanhadas de mobilizações por projetos alternativos ao modelo asilar dominante e a efetivação de um pensamento crítico sobre as práticas psiquiátricas.

Em 1987, o II Congresso de Trabalhadores de Saúde Mental, realizado na cidade de Bauru, São Paulo, acompanhou a efervescência política da época, distinguindo-se como marco histórico. São muitos os acontecimentos que propiciam considerá-lo emblemático. Dentre os diversos eventos, vale a pena citar: a primeira manifestação brasileira pública pelo fim dos manicômios; criação do Movimento Nacional de Luta Antimanicomial; o estabelecimento de 18 de maio 
como Dia Nacional de Luta Antimanicomial e a inclusão, em suas discussões, dos usuários e seus familiares (AMARANTE, 1998).

O lema "Por uma Sociedade sem Manicômio" e a denominação de Movimento Nacional de Luta Antimanicomial inauguram uma nova etapa do movimento (NABUCO, 2008), na qual se percebe um progressivo aumento na utilização dos materiais de divulgação. Slogans e imagens de apurado senso estético passam a compor as comunicaçóes do movimento.

\section{Processos}

O principal método utilizado foi de natureza qualitativa, sendo os cartazes analisados em seus discursos. O método de análise social de discursos propóe-se a desvelar os modos de produção dos sentidos dos objetos simbólicos, sejam eles enunciados, texto, pintura, fotografia, música ou outro qualquer. Os sentidos, porém, não se restringem aos objetos. Estão também, e principalmente, na relação em que estabelecem com o exterior e em suas condições de produção, ultrapassando as intençōes dos sujeitos (PINTO, 2002; ARAUJO, 2000; ORLANDI, 2000).

De acordo com Pinto (2002, p. 11), a Análise Social de Discursos-método que se apoia na Semiologia dos Discursos Sociais-tem por proposta "descrever, explicar e avaliar criticamente os processos de produção, circulação e consumo dos sentidos" dos materiais empíricos em seu funcionamento social. Araújo (2000) ressalta, na perspectiva do sentido, o que realmente importa: o processo.

A análise de discurso encontra complementação no contexto, não se limitando ao cartaz. Segundo Pinto (2002, p. 29), tratar os documentos independentemente dos contextos, "esquecendo-se de sua 'opacidade' ideológica, que a análise de discurso coloca em primeiro plano”, é considerar apenas seu valor documental. No texto, outros textos se fazem presentes. O texto é sempre composto por vozes que se originam de textos preexistentes. Ao analista cabe tentar entender o porquê de alguns terem sido escolhidos dentro de um universo infindo de outros que poderiam ser citados. E, ainda, observar o lugar social de onde vêm os textos citados, as condiçôes históricas que os envolvem e criar hipóteses para a heterogeneidade existente.

Para além dos sujeitos e da situação, as condiçôes de produçáo compreendem também a memória. Pensada em relação ao discurso, ela é tratada como interdiscurso (o já dito), que, além de determinar o intradiscurso (o que se está dizendo), permite ao 
analista, por meio da historicidade, perceber o que é relevante para o atual discurso sob análise (ORLANDI, 2000). Toda produção, circulação e consumo dos sentidos de um texto, na análise de Pinto (2002), passa pelas dimensôes da ideologia e do poder, dimensões que formam a semiose social.

Verón (2004) considera o ideológico algo que emerge da relação entre o texto e suas condições de produção e, por esse motivo, deixa marcas no texto. A cargo do analista está a procura pelas marcas deixadas na superfície textual. O poder emerge da relação do texto com seu "consumidor", propiciando condiçôes de reconhecimento. Ao analista é possibilitado observar os efeitos alcançados pelo texto em contextos sociais diferentes. Verón (2004, p. 60) comenta: "O poder de um discurso só pode ser estudado sobre outro discurso que é seu 'efeito"”.

Nossa análise dos cartazes, com olhar voltado para as premissas anteriores, estabelece como principal eixo operatório a relação entre o texto (o cartaz) e suas condiçôes sociais, institucionais e históricas de produção. No plano microanalítico, buscamos identificar as marcas deixadas por essas condiçôes de produção deslindando os fios do tecido discursivo em que se entrelaçaram vozes e discursos, ora em sinergia, ora em concorrência. Desse modo, percebemos, no movimento dos sentidos, o movimento dos atores e da luta antimanicomial.

Metodologicamente, o conceito mais utilizado foi o da enunciação, de Benveniste (2005). Utilizamos as noçôes de sujeito da enunciação e enunciador para identificar e recortar as vozes presentes no texto e o lugar por elas ocupado. O sujeito da enunciação mostra como o sujeito se define no discurso, e os enunciadores são as vozes chamadas a participar (ARAÚJO, 2000). A existência de discursos concorrentes (MAINGUENEAU, 1997) também aparece no trabalho de pesquisa. Discursos antimanicomiais se confrontam com discursos manicomiais e concorrem mesmo entre si. Outro conceito usado foi o de comunidade discursiva (Maingueneau, 1997), para marcar aqueles que estão envolvidos na produção e circulação do discurso antimanicomial. Assim, buscamos identificar metodologicamente os dispositivos de enunciação dos cartazes comemorativos da luta antimanicomial, considerandoos textos que não só expressam, mas também constituem essa luta marcada pela perspectiva contra-hegemônica.

O corpus extenso de análise foi formado pelos cartazes do acervo do Laboratório de Estudos e Pesquisas em Saúde Mental e Atenção Psicossocial (Laps) e os que foram obtidos com os Núcleos Antimanicomiais das diversas regióes do Brasil. O 
acervo constituído apresenta quantidade variável de materiais por região, embora algumas regiōes em alguma das décadas pesquisadas tenham grande quantidade de material e outras, quase nenhuma.

Após o levantamento desse material, constituímos um corpus específico pautado em critérios de ordem temática, geográfica e temporal. Quanto ao tema, foram privilegiados cartazes comemorativos do Dia Nacional de Luta Antimanicomial. Quando se configurou a impossibilidade de se localizar materiais especificamente com essa característica, por causa da falta de prática, em vários lugares de registro, para conservar esse tipo de documentaçáo, ou pela ausência de respostas aos nossos reiterados contatos, passamos a admitir, na composição do corpus, alguns materiais que se referiam a outros eventos, mas guardavam certa relação histórica com as ocasiōes comemorativas.

No decorrer da pesquisa, identificamos uma grande e importante produção realizada pelo Conselho Federal de Psicologia (CFP) com início na década de 1990, o que nos levou a incluir seus cartazes no corpus de análise.

Sobre a localizaçáo geográfica, o cruzamento desse critério com o anterior resultou em um cartaz por regiấo. Em alguns casos, não foi possível seguir esse critério adequadamente, por dificuldades específicas da pesquisa, mas não podemos afirmar que não tenham sido produzidos. A Região Centro-Oeste não está representada nos cartazes da década de 1990; eles são de outras regióes (Norte, Nordeste, Sul e Sudeste) e completados por um cartaz do CFP. O cartaz 1 é do Estado do Pará, o 2 foi produzido pelo CFP, o cartaz 3 pertence ao Estado de Minas Gerais, o 4 foi proveniente do Estado do Paraná e o cartaz 5 tem sua origem no Estado de Alagoas. O cartaz da Região Nordeste é do IV Encontro Nacional do Movimento Antimanicomial, realizado pelo Núcleo Antimanicomial de Alagoas, responsável pelo evento no ano de 1999. É o único dos cartazes dos anos 1990 que não é comemorativo do Dia Nacional de Luta Antimanicomial.

Para os anos 1990, enfocados neste artigo, foram escolhidos cartazes de 1997 por marcar a comemoração dos dez anos do encontro de Bauru, como já afirmado aqui, por ele ter se tornado um marco na história do Movimento da Reforma Psiquiátrica brasileira. No entanto, não foi possível localizar material com essa mesma característica nas regiôes Sul e Nordeste, sendo substituídos por uma peça comemorativa do Dia Nacional de Luta Antimanicomial de 1998 (Regiáo Sul) e outra de 1999 (Região Nordeste). 
Foram também analisados documentos históricos encontrados no Laps e os obtidos com os participantes do movimento, que acrescentaram informaçóes que acentuavam o contexto político e institucional de sua produção e circulação, relevantes para a pesquisa. Basicamente, eram jornais relacionados aos eventos desenvolvidos pelos produtores dos cartazes analisados, documentos iniciais ou finais de encontros ou congressos vinculados aos materiais de divulgaçáo estudados, folders complementares aos cartazes selecionados, documentos gerados pelos núcleos antimanicomiais vinculados aos materiais analisados.

Passamos, a seguir, à apresentação dos cartazes e da cena social dos anos de 1990.

\section{Os cartazes e suas condiçóes de produção}

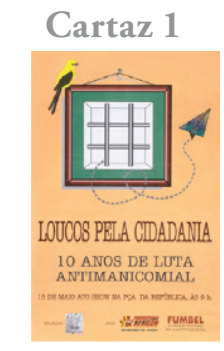

Fonte: arquivo Laps

\section{Cartaz 4}

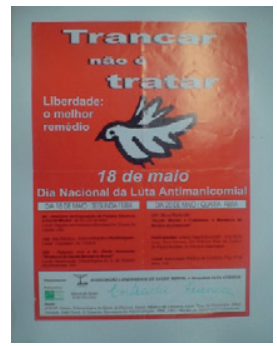

Fonte: arquivo Laps

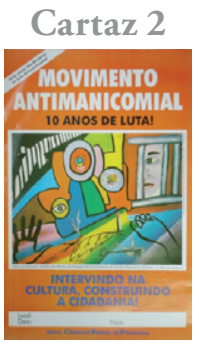

Fonte: arquivo Laps

\section{Cartaz 5}

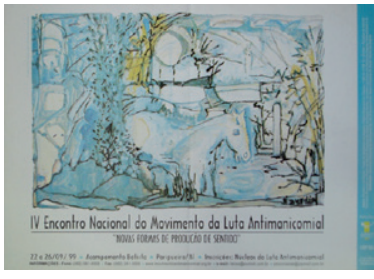

Fonte: arquivo Laps

\section{Cartaz 3}

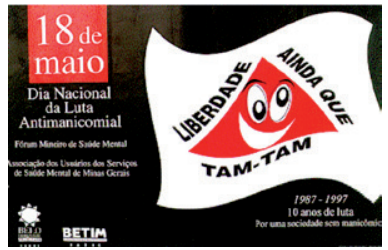

Fonte: arquivo Laps

1 Loucos Pela Cidadania - Belém, PA (1997)

2 Intervindo na Cultura, Construindo a cidadania- CFP (1997)

3 Liberdade Ainda que TAM -TAM - Belo Horizonte, MG (1997)

4 Trancar não é Tratar - Londrina, PR (1998)

5 Novas Formas de Produção de Sentido - Paripueira, AL (1999) 


\section{Cena social ${ }^{1}$}

Na saúde mental, a década começou com avanços. Em 1991, foi reformulada a transferência de recursos financeiros até entáo vinculados à internação e ao atendimento ambulatorial. A publicação da Portaria no 189/1991 pela Secretaria Nacional de Assistência à Saúde do Ministério da Saúde modificou a remuneração das internaçôes hospitalares, estabelecendo número máximo de diárias por $\mathrm{AIH}$ (Autorização de Internação Hospitalar), e contemplou novos procedimentos. Complementando tal avanço, foi baixada a Portaria no 224/1992, que promoveu diretrizes e normas para a assistência em saúde mental (YASUI, 2010).

No início dos anos de 1990, como assinalado por Maia e Fernandes (2002), os representantes administrativos do Estado se posicionaram a favor da inversão do tratamento hospitalar para o atendimento que privilegiasse a não internação. Em 1992, o Ministério da Saúde marcou sua posição com a campanha "Doença mental não é crime".

Os dez anos de luta antimanicomial foram comemorados em 1997. A data, simbolicamente muito significativa, direcionou nossa escolha pelos cartazes. Além dessa celebração, ocorreu o III Encontro da Luta Antimanicomial, em Porto Alegre. No evento, denominado "Por uma sociedade sem exclusôes", destaca-se a preocupação com a inserção do usuário na sociedade, estabelecida em uma proposta visando a superar as dificuldades de moradia e manutenção dos ex-internos dos hospitais psiquiátricos por meio de lares abrigados e pensóes protegidas (MAIA; FERNANDES, 2002). Os cartazes dos anos 1990 retratam o avanço antimanicomial em todas as regiōes do Brasil. Eles adquiriram um novo padrão. As cores, o lúdico e a irreverência são preponderantes. A cidadania, a liberdade e as questôes culturais compóem os temas enfocados nos slogans. 


\section{Dispositivos de enunciação}

\section{Cartaz 1}

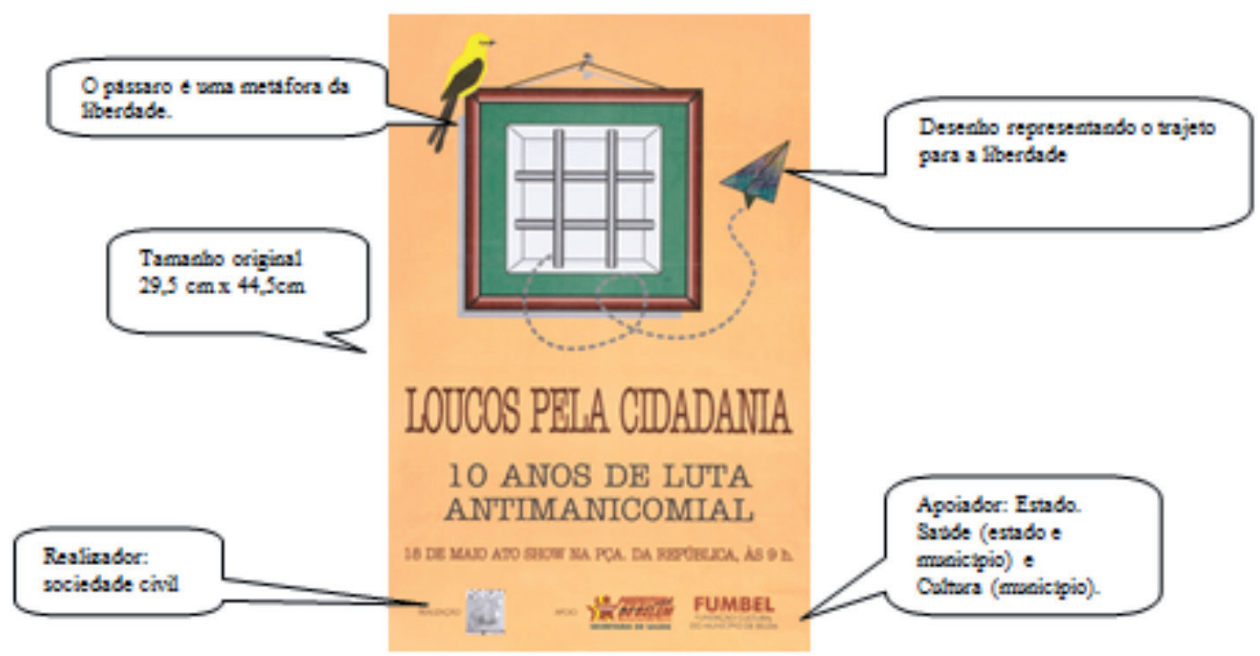

Fonte: Elaboração própria.

O sujeito da enunciação é o Fórum de Saúde Mental, com o papel de realizador. Como enunciadores, apresentam-se a Prefeitura de Belém-governo do Pará-, Secretaria de Saúde e Fundação Cultural do Município de Belém (Fumbel), que se posicionaram como apoiadores.

Aqui, os enunciadores comemoraram os dez anos de luta antimanicomial e, para tal, adotaram o slogan "Loucos pela Cidadania”. No cartaz, é informada a realização de um evento cultural com o intuito de celebrar o aniversário da luta. Os emissores instauraram seu lugar de poder a partir da fala sobre o manicômio, caracterizado como um quadro na parede, ou seja, algo que faz parte de uma lembrança, um fato já passado. $\mathrm{O}$ aviáozinho sai das grades, e o pássaro traduz o sentimento de liberdade. $\mathrm{O}$ antagonista foi trazido para a cena discursiva, porém como algo ultrapassado (comemora-se justamente a vitória obtida).

Podemos afirmar que a população foi o público desejado para o cartaz, uma vez que o evento, organizado na intenção de comemorar os dez anos antimanicomiais, ocorreu na forma de ato-show em praça pública de Belém. "Loucos pela cidadania" traz para a cena discursiva os loucos, mas não o louco confinado, amontoado e em 
grilhôes. O louco presente no cartaz da década de 1990 informa de modo lúdico seu desejo de cidadania, bem como reafirma a bandeira de luta. Esse cartaz remete à reflexão de Pealbart (1990, p. 137) quando enfatiza que o direito à desrazão significa "devolver um direito de cidadania pública ao invisível, ao indizível e até mesmo, por que não, ao impensável”.

O Fórum de Saúde Mental conseguiu apoio da Secretaria de Saúde e da Fundação Cultural do município para a produção do cartaz e do ato-show. Os enunciadores escolheram cores alegres, a imagem caracteriza o opositor como ultrapassado e o slogan lúdico brinca com as palavras. $\mathrm{O}$ ato-show corroborou a ideia do slogan, pois o espaço público selecionado se caracteriza historicamente como local de manifestaçôes dos cidadãos por seus direitos e demandas. A ocupação desse espaço pelos loucos demonstra ser um ato simbólico de conquista da cidadania.

\section{Cartaz 2}

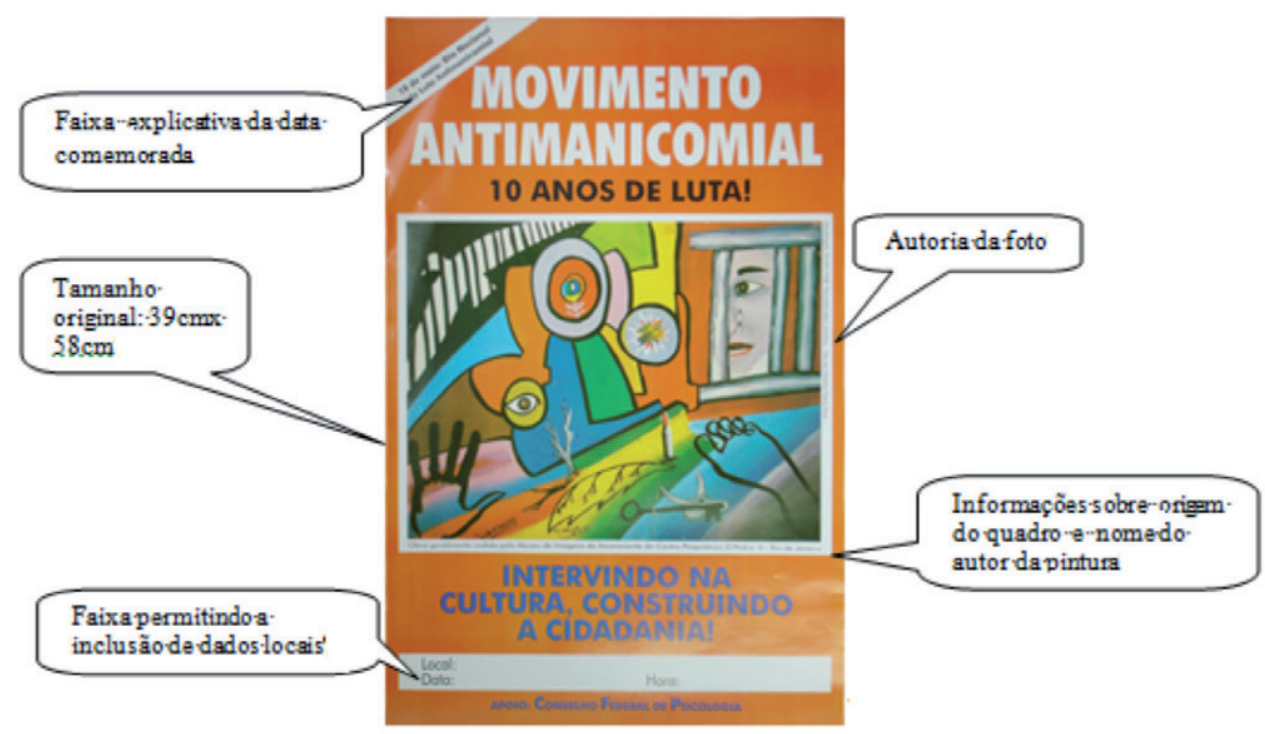

Fonte: Elaboração própria.

A Lei 5.766, de 1971, criou o Conselho Federal de Psicologia e os Conselhos Regionais. Ao CFP foi atribuída jurisdição em todo o território nacional e supremacia sobre os Conselhos Regionais. No ano de 1973, o CFP empossou seu primeiro conselho, e, em 1974, o CRP contabilizava 895 psicólogos inscritos. No ano 
seguinte, contavam-se 4.951. Na década de 1980, o número estimado de inscritos foi em torno de 50 mil profissionais (SOARES, 2010).

O CFP destacou-se, nos anos 1990, como apoiador, patrocinador e realizador não só de cartazes, mas também de eventos e publicaçôes relacionadas ao Movimento Antimanicomial. O símbolo do Conselho Federal de Psicologia - tornou-se presente em grande número de cartazes do Movimento Nacional de Luta Antimanicomial. Uma das açóes mais relevantes do CFP foi a distribuição de cartazes comemorativos do Dia Nacional de Luta Antimanicomial por todo o Brasil. Maria Ermínia Ciliberto, presidente do CFP, em entrevista a nós concedida, comentou que a função dos cartazes é integrar o movimento.

Algumas vezes, o logotipo do CFP, nesses cartazes, é inserido em parceria com outras entidades, tais como conselhos regionais. Segundo Ciliberto, o Conselho de Psicologia, diferentemente de outros, estabelece uma política de desenvolvimento da psicologia por igual em todo o país (assim como apoio aos movimentos sociais no Brasil). No caso dos cartazes, aqueles que possuem condiçôes financeiras são seus próprios produtores, já aqueles que não dispóem de recursos podem utilizar os cartazes do CFP. "A gente tem uma possibilidade de apoio ao movimento dentro do que é permitido pelo Tribunal de Contas, em tudo que possa ter três orçamentos. Assim, podemos pagar algumas coisas e outras não. Não é o apoio ideal, mas o apoio possível”, afirma.

Normalmente, os cartazes do CFP não apresentam identificação do ano e, por essa razão, é possível repeti-los por diversos anos. A seguir, trazemos alguns exemplos:

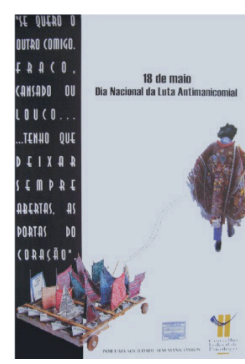

(2a)

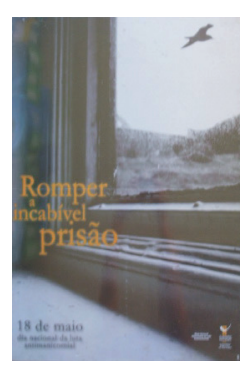

(2b)

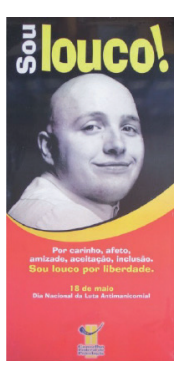

(2c)

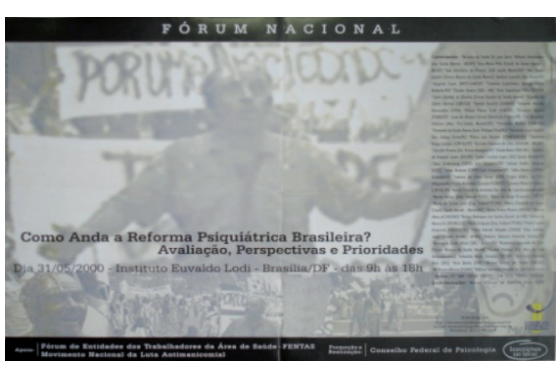

(2d)

Fonte: arquivo Laps 
O cartaz analisado é de 1997, e a identificação da data foi possibilitada pela informação dos dez anos de luta antimanicomial. No centro, há o registro de uma pintura; na parte de cima, informaçóes sobre a data comemorativa; já na parte de baixo, um slogan, uma faixa branca a ser preenchida e o apoio. A figura do realizador não foi mencionada. Assim, consideramos como enunciadores: o pintor Darcângelo, autor da pintura; o fotógrafo Antônio Viana Alves, que a fotografou para o cartaz; o Museu de Imagens do Inconsciente, em cujo acervo encontra-se a obra; o CFP, que atuou como apoiador.

O espaço em branco poderia ter sido preenchido por algum serviço, Secretaria de Saúde ou núcleo do movimento antimanicomial de qualquer lugar do Brasil, tornandose assim o sujeito da enunciação. O exemplar do cartaz analisado, no entanto, trouxe o espaço em branco, vazio, propiciando que o lugar do sujeito da enunciação seja ocupado por duas entidades. Em primeiro plano, o Movimento Antimanicomial preenche boa parte do espaço e se destaca no conjunto dos elementos gráficos. É ele o aniversariante que comemora dez anos de luta. Todavia, o CFP também dessa forma se enuncia, embora com letras pequenas, ao pé do cartaz. Tal fato ocorre pelo uso da mesma cor e a proximidade espacial com o slogan "Intervindo na cultura e construindo a cidadania”, tornando-se, portanto, o agente dessa intervenção. Se, na cena social, o CFP é um dos principais agentes do movimento, na cena discursiva estabelece-se uma concorrência entre ele e o movimento pelo lugar do sujeito da enunciação.

O emissor busca instaurar seu espaço de poder a partir da forma de intervenção proposta. Ele aponta a cultura como instrumento parase adquirir cidadania. A pintura, ao mesmo tempo, retrata o infortúnio ocasionado pelo manicômio, o antagonista representa o modo de intervenção proposto no slogan. Seus destinatários foram os Conselhos Regionais de Psicologia, determinantes da circulação dos cartazes. Coube a eles não só sugerir a melhor forma de atuação, como também instigar a realização de um evento comemorativo, além de se tornarem ainda emissores antimanicomiais.

A produção do cartaz permitiu sua afixação divulgando o Dia Antimanicomial ou servindo para tornar público um evento organizado no âmbito local, que pode ter tido participação direta das pessoas ou não, ter sido gratuito ou pago, obedecido à sugestão do CFP ou não.

Para comemorar os dez anos de luta antimanicomial, o CFP escolheu um cartaz de cor vibrante e inseriu nele a imagem do sofrimento trazido pelo manicômio. De forma didática, porém artística, mostrou como deveria ser a ação antimanicomial. 
A circulação provavelmente atingiu diversas regiôes do Brasil ou até mesmo todas. $\mathrm{Na}$ explicação de Ciliberto, os cartazes foram distribuídos para os conselhos regionais. Alguns os receberam, mas os destinaram às gavetas. Outros terão feito um evento, encaminhado-os para núcleos ligados ao movimento, e propuseram uma parceria com os usuários, configurando-se um processo de adaptação aos interesses e contextos locais.

Uma rede de significaçóes emerge do cartaz. O destaque fica por conta da cor abóbora muito viva, fazendo com que ele chame a atenção. A atenção do leitor se divide entre o nome do movimento e a pintura, protagonista e antagonista disputam espaço. $\mathrm{O}$ nome do movimento foi escrito em letras brancas grandes. A pintura que retrata o manicômio, apesar de melancólica, recebeu o lugar central, ou seja, no meio do cartaz, e traz muitas cores vivas. Ela retrata um rosto com lágrimas preso atrás das grades, observando o que restou de si. A leitura que se deseja estabelecer, a partir da pintura, é a dos males ocasionados pelo aprisionamento manicomial, que, além disso, serve de ponte para o slogan, seu maior destaque, na parte inferior do cartaz, sobressaindo menos. A cor azul foi escolhida para o slogan e o apoio, e, entre eles, há uma faixa branca que permite uma intervenção. O CRP, valendo-se de letras pequenas no final do cartaz, apresentou-se de forma discreta como apoiador.

\section{Cartaz 3}

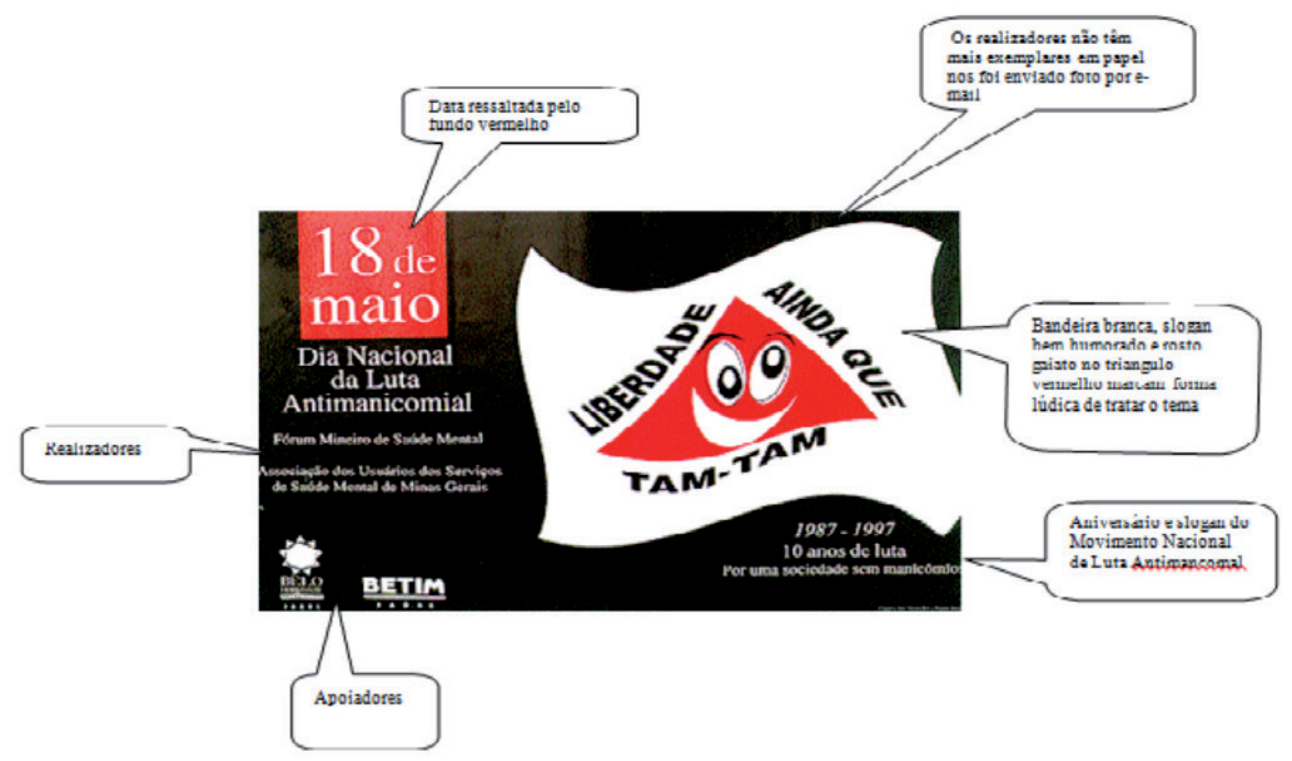

Fonte: Elaboração própria 
O Fórum Mineiro da Saúde Mental (FMSM), composto de trabalhadores, usuários e familiares da rede de saúde mental de todo o estado, e a Associação dos Usuários dos Serviços de Saúde Mental de Minas Gerais (Asussam), idealizadores do cartaz que agora analisamos, são organizaçóes antimanicomiais de grande atuação no Estado de Minas Gerais. Foram criadas em 1994, e o impulso para seu estabelecimento ocorreu a partir da participação de uma delegação de Minas Gerais no I Encontro Nacional da Luta Antimanicomial, em Salvador, no ano de 1993, bem como da escolha do estado mineiro para sediar o II Encontro Nacional da Luta Antimanicomial.

Desde a sua estruturação, o FMSM e a Asussam elaboram cartazes comemorativos do Dia Nacional de Luta Antimanicomial. A produção das organizaçôes remonta à sua fundação; a partir de então, distribuem cartazes no dia 18 de maio anualmente, como estes exemplos, produzidos em parceria pelas duas organizaçôes.

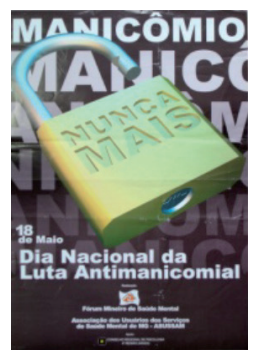

(3a)

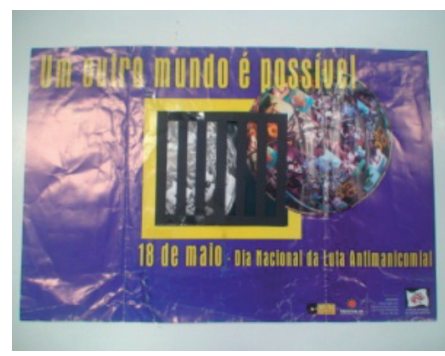

(3b)

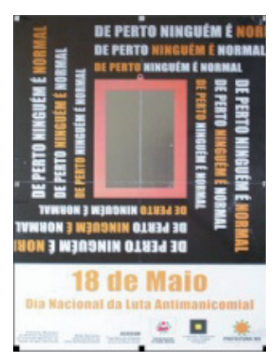

(3c)

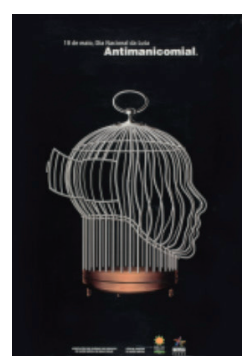

$(3 \mathrm{~d})$

Fonte: arquivo Laps

O cartaz 3 traz do lado direito uma enorme bandeira com os dizeres "Liberdade Ainda que TAM-TAM”. A bandeira símbolo do FMSM recebeu destaque no cartaz. O nome do fórum surge no meio do cartaz, do lado esquerdo, com o da Associação dos Usuários dos Serviços de Saúde Mental de Minas Gerais. Na parte inferior, do lado esquerdo, estão as logos das Secretarias de Saúde de Belo Horizonte e de Betim. Tal disposiçấo nos propicia considerar nossos enunciadores o FMSM, a Asussam, a Secretaria de Saúde de Belo Horizonte e a Secretaria de Saúde de Betim. Não há, no cartaz, nenhuma informação explicitando quem são os realizadores e os apoiadores; assim, pela posição ocupada e as modalidades (texto e logomarca), 
podemos entender que as organizaçôes da sociedade civil são os realizadores e as Secretarias de Saúde dos municípios, os apoiadores. Já como sujeitos da enunciação, apresentam-se o Fórum Mineiro de Saúde Mental e a Associação dos Usuários dos Serviços de Saúde Mental de Minas Gerais.

Os emissores buscaram instituir sua fala autorizada (portanto, seu lugar de poder) pelo mecanismo da intertextualidade, produzindo um paralelo entre a Inconfidência Mineira e a luta antimanicomial. A bandeira, com o triângulo vermelho, trouxe um rosto gaiato e o slogan que parafraseia o slogan inconfidente. Os emissores se posicionaram por meio da irreverência, mas, ao mesmo tempo, produziram uma "contaminação" de açôes em confronto lançando mão da legitimidade de um dos maiores símbolos da luta pelo rompimento das estruturas de dominação e pela liberdade, a Inconfidência Mineira. Assim, intentaram produzir o efeito de neutralização de uma possível rejeição ou antagonismo. A metáfora "bandeira de luta” emerge com força total dessa produção gráfica.

Com base na análise do dispositivo, é possível afirmar que os destinatários foram a população em geral e os antagonistas aqueles que defendem os manicômios, ainda que apenas explicitados no slogan do movimento: ao pedir uma sociedade sem manicômio, os antimanicomiais revelam a existência dos manicômios. Os enunciadores trouxeram para a cena novos enunciadores, os inconfidentes e os TAM-TAM entraram em cena respectivamente afirmando e reclamando a liberdade como um bem inalienável.

A produção aqui analisada não menciona nenhum evento, somente a divulgação da data comemorativa e das bandeiras de luta antimanicomiais. Miriam Abou-Yd, participante do Fórum Mineiro de Saúde Mental desde o início de sua composição, explicou que nos cartazes são incluídos todos os principais parceiros que ajudaram a realizar o 18 de maio daquele ano, não só os envolvidos na confecção do cartaz. A entrevistada não soube dar informaçóes específicas sobre se ocorreram ou não eventos no ano de 1997. Os cartazes do Dia Nacional de Luta Antimanicomial variaram conforme o auxílio obtido. No processo para obter recursos, contavam com assessores, convidavam três ou quatro artistas, faziam uma proposta e criavam uma comissão julgadora. Alguns cartazes foram produzidos pela Assessoria de Comunicação da Prefeitura de Betim em discussão com o fórum e a Asussam. Outros ainda foram elaborados por um artista amigo do fórum. 
Segundo Abou-Yd, são rodados, normalmente, cerca de dois mil cartazes, distribuídos para a rede de saúde mental (Caps, Centros de Convivência, Centros de Saúde etc.) das prefeituras de Minas Gerais, instituiçóes formadoras em especial no campo da saúde, todas as regionais dos conselhos de classe da área da saúde, Ministério Público, Conselhos de Saúde, Secretarias de Educação, Assistência Social, Cultura etc., entidades dos direitos humanos, inclusão produtiva, população de rua e as demais parcerias que se estabeleceram ao longo do tempo.

Nas redes de significações que surgiram como efeito discursivo do cartaz, destacouse a bandeira. Diferentemente de outros produzidos pelas duas organizaçóes, ela não ocupa o lugar de logomarca do fórum. Uma pequena bandeira, com o nome do fórum, na parte de baixo, foi o formato encontrado em outros cartazes elaborados pelas duas organizaçóes. Já no cartaz analisado, ela ocupa espaço privilegiado. A cor vermelha relacionada aos movimentos revolucionários preencheu o dia de comemoração e o triângulo. A bandeira do Estado de Minas Gerais tornou-se referência na escolha da cor. Ambas as bandeiras apresentaram forte alusão à da Inconfidência. $\mathrm{O}$ bom humor demarcou a atuação antimanicomial e os autores brincaram com a nominação do sujeito com transtorno mental. A denominação popular TAM-TAM promoveu um tom leve à reivindicação de liberdade, bem como a forma quase infantil retirou a carga semântica negativa histórica e socialmente constituída da palavra "louco", que poderia causar rejeição e polêmica. O termo TAM-TAM ofereceu sentido alegre e inofensivo aos loucos, desarticulou a relação entre loucura e perigo. Abaixo da bandeira do fórum, foi incluída uma menção aos anos de luta e o slogan do Movimento Nacional de Luta Antimanicomial, produzindo-se assim o reiteramento do slogan da bandeira.

A intertextualidade com a bandeira utilizada na Conjuraçáo Mineira e, posteriormente, em Minas Gerais, não deixa esquecer que a questão da liberdade perpassa a história local. A cor vermelha, que também consta na bandeira do estado, fortaleceu a importância que o olhar revolucionário adquiriu para os mineiros. Nas repetiçóes, as questóes antimanicomiais se aproximaram daquelas valorizadas pela população, sendo atingida nos aspectos que lhe causam grande orgulho. 


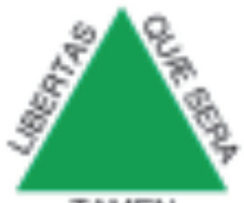

TAMEN

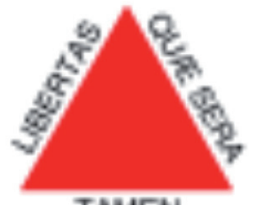

TAMEN

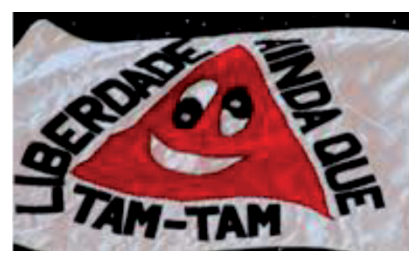

Bandeira do Fórum

Mineiro de Saúde Mental

\section{Cartaz 4}

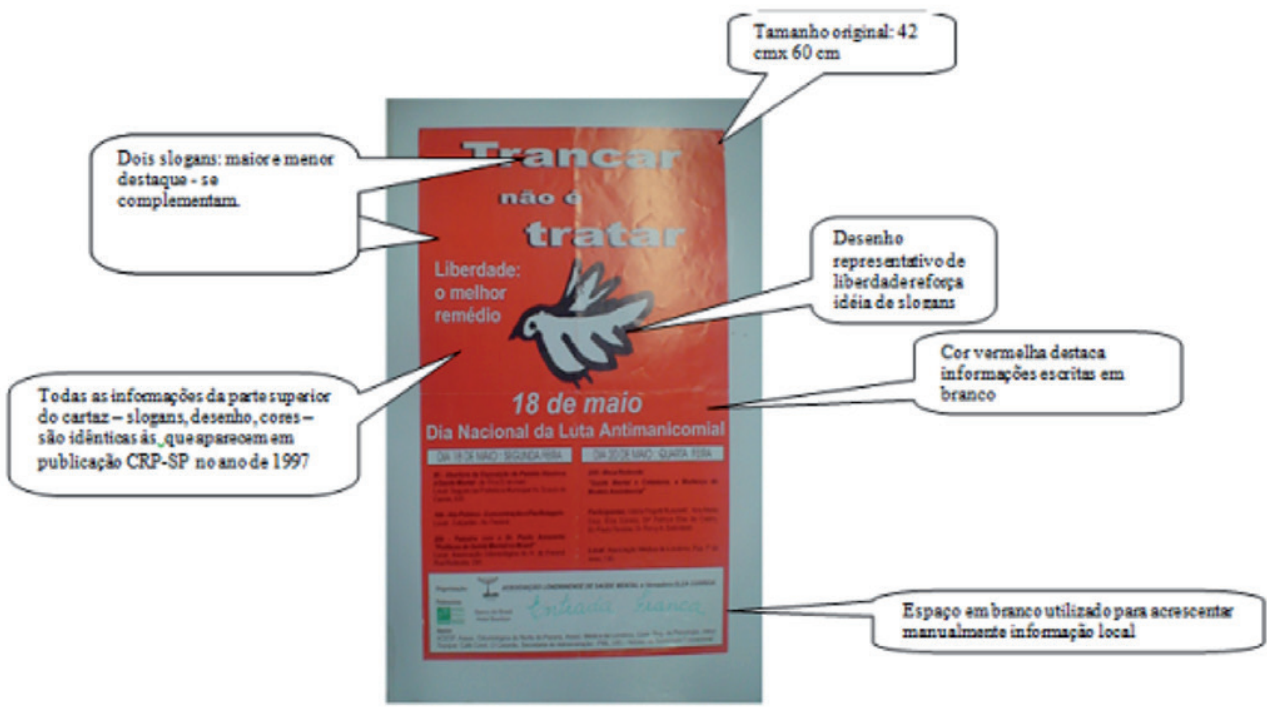

Fonte: Elaboração própria.

A Regiāo Sul do Brasil, como as outras, conta com grande número de organizaçóes da sociedade civil (ONGs). As ONGs, formadas principalmente por usuários, familiares e profissionais, estão distribuídas nas capitais e no interior, nos três estados da região.

Uma dessas organizações é a Associação Londrinense de Saúde Mental (ALSM). Não governamental e sem fins lucrativos, foi fundada em 1997 por familiares e profissionais, que, preocupados com a qualidade da atenção oferecida na área da 
saúde mental, resolveram se organizar. Seu principal objetivo é a luta pelos direitos de dignidade e cidadania dos portadores de sofrimento psíquico e de seus familiares. ${ }^{2}$

O cartaz analisado divulgou o evento que ocorreu nos dias 18 e 20 de maio, provavelmente no ano de 1998. Aqui, conjugamos a informação do calendário e do professor Paulo Amarante. Para a comemoraçáo do Dia Nacional de Luta Antimanicomial, foi realizada uma atividade cuja programaçáo apresentava-se no cartaz: uma exposição, um ato público, palestra com o pesquisador Paulo Amarante abordando o tema "Políticas de Saúde Mental no Brasil", além da mesa-redonda que trouxe o tema "Saúde Mental e Cidadania, a mudança do modelo assistencial”, com a presença de atores destacados do movimento.

Em uma faixa, ao final do cartaz, encontramos como organizadores a Associação Londrinense de Saúde Mental e a vereadora Elza Correa; como patrocinadores, a Secretaria Municipal de Saúde da Cidade de Londrina, o Banco do Brasil e o Hotel Bourbon; na função de apoiadores, Acesf, Associação Odontológica do Norte do Paraná, Associação Médica de Londrina, CRP, Jabur, Toyopar, Café Coral, O Casarão, Secretaria de Administração (PML), Universidade Estadual de Londrina (UEL) e seu Núcleo de Tecnologia Educacional.

A ALSM, no ano seguinte de sua criaçáo, procurou marcar o Dia de Luta Antimanicomial com um importante evento. Notamos que houve um esforço da organização em prol da realização do evento, revelado pelos seguintes fatores: os organizadores requisitaram a presença de personalidades da academia; criaram um ato público com panfletagem; conseguiram patrocínio, aqui aparentemente financeiro; além de apoio de diversos segmentos. Consideramos sujeitos da enunciação os organizadores do evento, portanto: Associação Londrinense de Saúde Mental. Os nomes foram dispostos na parte de cima da faixa branca com destaque. Há, na figura da vereadora como organizadora, o entendimento de que ela foi capaz de tornar o evento exequível.

Ao conseguirem organizar um evento com diversas etapas, ocupando vários locais da cidade e contando com a colaboraçáo de muitos segmentos sociais, os emissores instituíram um lugar de poder para si. Tiveram variados interlocutores de acordo com a etapa do evento, algumas delas abertas a um público amplo, e outras destinadas a um público interessado nas questôes da saúde mental. Os antagonistas, como ocorre em outros cartazes analisados, são aqueles que fazem circular uma fala pró-manicomial, representados discursivamente como os que não tratam, mas trancam. 
Os enunciados são dois e se completam. No primeiro, afirma-se por meio da negação. As palavras "trancar" e "tratar" opóem-se entre si. Apesar de ambas terem sido escritas com letras maiores comparadas ao restante, na oposição "tratar" recebeu letras menores. $\mathrm{O}$ enunciado principal nega que o tratamento possa ocorrer por meio do confinamento. Deixa ao receptor a pergunta: se tratar não é trancar, então qual forma e tratamento devem ser adotados? O desenho e o enunciado, inseridos na parte de baixo, complementam o primeiro enunciado, pois indicam como remédio a liberdade.

O cartaz aparenta leveza; tal aspecto é proporcionado pela figura do pássaro branco, estilizado, em sua parte central, fazendo referência à liberdade. Incluído entre o slogan principal e a data comemorativa, o pássaro reforça o slogan secundário "Liberdade: o melhor remédio".

\section{Cartaz 5}

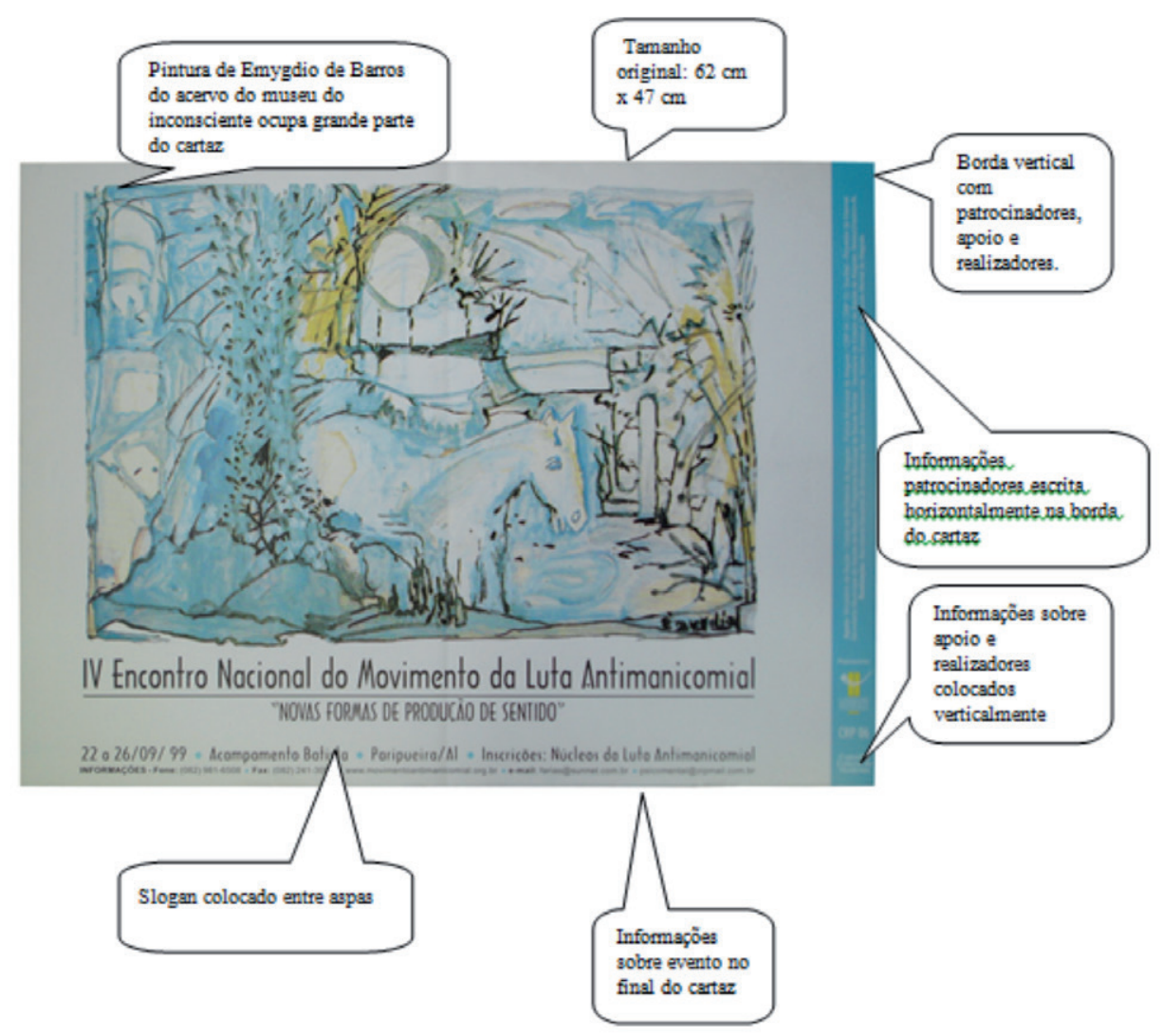

Fonte: Elaboração própria. 
O IV Encontro Nacional do Movimento de Luta Antimanicomial ocorreu no período de 22 a 26 de setembro de1999, em Maceió. Cerca de 1.500 usuários, familiares e técnicos participaram do evento, uma homenagem à dra. Nise da Silveira ${ }^{3}$. Na ocasião, foram abordados alguns temas, tais como: alternativas de moradia para os usuários, cooperativas sociais, financiamentos e redirecionamento dos recursos pertinentes à Saúde Mental para os serviços substitutivos; aprovação, na Câmara dos Deputados, do texto que propóe a extinção progressiva dos manicômios ${ }^{4}$. As mesas-redondas possibilitaram o debate de questóes significativas para o movimento e orientadoras das práticas institucionais realizadas em todo o país, questóes que colocavam em pauta o amparo legal e a viabilização de produçóes de novos sentidos na construção da identidade de indivíduos portadores de sofrimento psíquico (PORTO, 1999).

O cartaz anunciava o IV Encontro Nacional do Movimento de Luta Antimanicomial. Para tanto, lançava mão de uma obra do pintor Emygdio de Barros e o slogan "Novas Formas de Produçâo de Sentidos". Como ocorreu em outras peças já analisadas, os emissores desse cartaz não assumem com clareza o lugar de sujeitos da enunciação, que é percebido de maneira indireta pelo título do evento (Encontro do Movimento) e pelo endereço da sua página na internet, $<$ www.movimentoantimanicomial.org.br>, inserido de forma discreta. Também os enunciadores têm sua presença graficamente minimizada: os patrocinadores (CFP, CRP- 06, CFM), os apoiadores (Ministério da Saúde/Corpo de Bombeiros de Alagoas/Polícia Municipal de Alagoas, CRP 15/ Sun Net-Provedor de Internet/ Secretaria Municipal de Saúde Mental/ Secretaria de Estado de Saúde de AL /SEsau UNipsico-AL), os realizadores do Movimento Nacional de Luta Antimanicomial e Emygdio, autor da tela. $\mathrm{O}$ apoio, realização e patrocinadores foram colocados numa faixa azul do lado direito. Acompanham o sentido das informaçóes do cartaz apenas os patrocinadores. Os apoiadores e realizadores, inseridos verticalmente, são de difícil leitura, ao contrário do que ocorre com os nomes dos patrocinadores, que são fáceis de serem entendidos.

O emissor procura instaurar um lugar de poder através do cartaz, mas, ao propor novas formas de produçáo de sentido, apresenta-se de forma pouco acessível. $\mathrm{O}$ slogan não é de fácil compreensão, trata-se de um conceito teórico, conhecido por poucos e sujeito a muitas interpretaçôes. Em seu uso, percebe-se uma associação com a construção da identidade de indivíduos portadores de sofrimento psíquico. 
Há de se lembrar que é no ano de 1999 que a Lei no 10.216 volta a tramitar na Câmara; são liberados, ainda, recursos para 400 Caps e estabelecido um bônus de incentivo para a desinstitucionalização. Baseados nessas condições históricas, os atores antimanicomiais objetivam transformar a relação da sociedade com as pessoas em sofrimento mental. Entre os temas discutidos no encontro estão alternativas de moradia para os usuários, cooperativas sociais e os serviços substitutivos, evidenciando a criação de um novo processo de significação, com a proposta de novas formas de produção de sentido. O slogan, presente neste e em outro cartaz do encontro, foi o tema do IV Encontro Nacional de Luta Antimanicomial. Os destinatários foram os técnicos, usuários e familiares, aqueles que desejavam participar do encontro e os que pensavam em produzir novas formas de sentido na construção da identidade dos indivíduos com transtorno mental. Uma marca comum, seguida em todos os cartazes do movimento, é a polêmica implícita no enunciado do slogan, que, ao propugnar novas formas de produção de sentido, traz para a cena enunciativa os responsáveis pelas antigas formas de sentido, anunciando e possibilitando prever o tom do debate.

A pintura de Emygdio, pertencente ao acervo do Museu de Imagens do Inconsciente e escolhida para apontar os novos caminhos propostos, recebeu grande destaque na concepção do cartaz.

Artista reconhecido internacionalmente por seu trabalho, sua obra imprime significação ao slogan "Novas Formas de Produção de Sentido" por representar não só o potencial artístico de pessoas com transtornos mentais, geralmente consideradas incapazes, como também novos métodos de tratamento desses transtornos.

\section{Cultura, liberdade e cidadania como eixos temáticos}

Nos anos 1990, constatamos significativa transformação na abordagem dos temas da área da saúde mental. Cultura, liberdade e cidadania nos conduziram pelas novas formas de produzir sentidos antimanicomiais. As cores, o lúdico e a irreverência tomaram conta dos cartazes produzidos preponderantemente pela sociedade civil organizada, mostrando um momento de crescimento e força do Movimento Nacional de Luta Antimanicomial (MNLA). Os estados, municípios e governo federal estiveram presentes frequentemente como apoiadores. CFP e o MNLA circularam em algumas ocasiōes como sujeitos das enunciaçôes e em outros como enunciadores. Em outros termos, ao mesmo tempo em que operavam como apoiadores dos movimentos locais, eles forneciam diretrizes para a atuação destes movimentos. 
A luta "Por uma sociedade sem manicômios" apresentou-se com avanços e eles estiveram representados nos cartazes. O momento impôs discussóes sobre formas de intervenção (cartazes 2, 4 e 5) e os cartazes de alcance nacional (2 e 5) foram acompanhados de pinturas realizadas por artistas do Museu de Imagens do Inconsciente. Neles estabeleceu-se um diálogo com trabalhos pioneiros, indicando aos atores das diversas regiōes do Brasil outras possibilidades de intervenção. O cartaz 4, produzido localmente, apontava o fim do confinamento como melhor tratamento.

Podemos observar, nos cartazes da década de 1990, o registro da preocupação daquele momento de se colocar na esfera pública a questão da cidadania ampliada. Nos cartazes articulou-se esta com a cultura (cartaz 2) e com a liberdade (1 e 3). A Conjuração Mineira, ressaltada no cartaz 3, não nos deixa esquecer que cidadania e liberdade são conceitos que se encontram. O conceito construído em bases iluministas imprime à racionalidade grande importância. $\mathrm{O}$ sujeito louco, não sendo portador da racionalidade, sofre exclusão da cidadania. A reivindicação, marcada nos cartazes, objetivou ampliar o conceito de cidadania, buscou construir uma sociedade mais tolerante, que aceitasse a participação do diferente.

Para alcançar este objetivo, os cartazes produzidos localmente (Minas Gerais, Londrina e Belém) utilizaram-se bastante das cores, dos desenhos leves e slogans fortes, aproximando-se visualmente assim de sua estratégia discursiva. O uso de imagens conjugadas a frases de efeito foi uma característica dos cartazes da década de 1990. Em todos eles, as condições de confinamento foram lembradas, assim como aquelas que envolvem a situação de não confinamento. Imagens e frases dialogavam entre si e alternavam as referências.

As conquistas políticas ocorridas nos anos 1990, o crescimento do CFP como força pública dentro do movimento e a expansão dos núcleos antimanicomiais, fóruns e associaçôes fizeram daqueles anos um tempo um tempo de consolidação das práticas antimanicomiais, que abriram caminho para os avanços normativos ocorridos nos anos de 2000.

Em 6 de abril de 2001, o Congresso Nacional decretou e a Presidência sancionou a Lei 10.216. A aprovação ocorreu na forma de um substitutivo do Projeto Paulo Delgado. Em seu formato original, o projeto tramitou por 12 anos no Congresso Nacional. A lei dispóe sobre a proteção e os direitos das pessoas com transtorno mental, mas não institui mecanismos precisos direcionados à progressiva extinção dos manicômios. 
No ano de 2002, uma série de normatizaçôes do Ministério da Saúde instituiu mecanismos para a redução dos leitos psiquiátricos em todo o Brasil. Há de se destacar o Programa Nacional de Avaliação do Sistema Hospitalar/Psiquiatria (PNASH/ Psiquiatria), o Programa Anual de Reconstrução da Assistência Hospitalar Psiquiátrica no SUS (PHR) e o Programa de Volta para Casa.

Hoje, passados tantos anos da reforma e duas décadas das abordagens e posicionamentos das lutas que estiveram retratados nos cartazes, estamos diante de uma outra luta, para manter o conquistado. Existe uma preocupação, por parte dos trabalhadores de saúde mental, relacionada à consolidação da rede de atenção psicossocial, principalmente diante do avanço da precarização dos vínculos no setor público e da possibilidade de investimentos parcos no serviço de desinstitucionalização. Nota-se ainda o avanço das forças conservadoras que lucraram, por muitos anos, com hospitais que amontoavam pacientes psiquiátricos e obtinham fabulosos lucros; desacreditadas cientificamente e condenadas sob o juízo ético, voltam a tentar impor sua visão de mundo.

Neste nosso estudo, tomando-se a comunicação como lugar de reflexão, foi possível re-conhecer o contexto sócio-histórico e relacioná-lo aos processos em que o movimento da Reforma esteve inserido. Ao analisarmos as ideias expressas no material de divulgação, compreendemos para quais outras forças políticas os militantes dirigiam seu discurso, quem eram seus opositores e de que maneira pretendiam transformar a realidade naquele momento. Nos tempos atuais, a comunicação está mais que nunca presente nessa luta, tanto do lado de quem deseja desconstruir as conquistas como de quem está potencialmente a nosso favor. ${ }^{5}$

\section{Referências}

AMARANTE, P. D. Loucos pela vida: a trajetória da Reforma Psiquiátrica no Brasil. 2. ed. Rio de Janeiro: SDE/ENSP, 1998.

ARAÚJO, I. S. A reconversão do olhar: prática discursiva e produção dos sentidos na intervenção social. São Leopoldo: Editora Unisinos, 2000.

BENVENISTE, E. Problemas de linguistica geral - I. 5. ed. Campinas: Pontes, 2005.

CONSELHO REGIONAL DE PSICOLOGIA (6a Região). Trancar não é tratar. São Paulo, 1997. MAIA, R. C. M.; FERNANDES, A. B. O movimento antimanicomial como agente discursivo na esfera pública política. Revista Brasileira de Ciências Sociais, São Paulo, v. 17, n. 48, fev. 2002. 
MAINGUENEAU, D. Novas Tendências em análise do discurso.3ed.Campinas: Pontes,1997

NABUCO, E. Da reclusão à criação: construção da memória dos usuários do Movimento Nacional de Luta Antimanicomial. 2008. Dissertação (Mestrado em Memória Social) Universidade Federal do Estado do Rio de Janeiro, Rio de Janeiro, 2008.

ORLANDI, E. P. Análise de discurso: princípios e procedimentos. Campinas: Pontes, 2000.

PEALBART, P. P. Manicômio mental: a outra face da clausura. In: LANCETTI, A. (Org.). Saúde loucura. 2. ed. São Paulo: Hutitec, 1990. p. 131-138.

PINTO, M. J. Comunicação e discurso: introdução à análise de discursos. 2. ed. São Paulo: Hacker, 2002.

PORTO, K. F. et al. Noticia: IV Encontro Nacional da Luta Antimanicomial. Psicologia Teoria e Pesquisa, Brasília, v. 15 n. 1, p. 077-077, 1999. Disponível:

< https://revistaptp.unb.br/index.php/ptp/article/view/1493>. Acesso em: 27 nov . 2013

SOARES, A. R. A Psicologia no Brasil. Psicol. cienc. prof. v. 30, n. esp. p. 8-41, 2010. Disponível em: <http://dx.doi.org/10.1590/S1414-98932010000500002>. Acesso 04 nov. 2013.

VERÓN, E. A produção de sentidos. São Paulo: Cultrix, 1980.

. Fragmentos de um tecido. 4. ed. São Leopoldo, RS: Editora Unisinos, 2004.

YASUI, S. Rupturas e encontros: desafios da Reforma Psiquiátrica brasileira. Rio de Janeiro: Editora Fiocruz, 2010.

\section{Notas}

1 "Cena social" foi um termo utilizado na tese com a atribuição de aproximar o leitor do momento sócio-histórico do movimento e do grupo de cartazes em pauta, é um dos dois conceitos que sustentação da análise, sendo o outro cena discursiva.

${ }^{2}$ Disponível em: < http://alsaudemental.blogspot.com.br/2011/08/novidade-no-site-da-alsm.html>.

${ }^{3}$ Nise da Silveira, médica psiquiátrica, natural do estado das Alagoas, falecida aos 94 anos, no mês de outubro de 1999, desenvolveu, na cidade do Rio de Janeiro, grande parte do seu trabalho. No Centro Psiquiátrico Pedro II (CPPII), desenvolveu ateliês de modelagem e pintura para os internos, privilegiando formas de tratamento nâo agressivas, e lá viu surgir artistas plásticos que adquiriram renome internacional. Em 1952, no CPPPII, fundou o Museu do Inconsciente, um centro de estudo e pesquisa destinado à preservação dos trabalhos produzidos nos ateliês da instituição. Em 1956, desenvolveu o projeto da Casa das Palmeiras, uma clínica voltada para o tratamento de pacientes externos. Foi membro fundadora da Societé Internationale de Psychopathologie de l'Expression, sediada em Paris. As suas pesquisas a tornaram reconhecida internacionalmente e agraciada com prêmios e condecorações em diversas áreas da ciência. (www.museuimagensdoinconsciente.org. br/html/nise.html). 
${ }^{4}$ Esse projeto, de autoria do Deputado Paulo Delegado (PT/MG), em tramitação desde 1989 no Congresso Nacional, já obteve aprovação nas duas casas, Câmara e Senado, havendo retornado para a Câmara dos Deputados para votação final e definitiva junto a substitutivo do senador Sebastião Rocha (PDT/AP). A votação será em acordo entre o texto do projeto original de 1989 e esse substitutivo.

${ }^{5}$ W. E. Santo realizou a pesquisa original e redigiu o artigo. I. Araujo orientou a pesquisa, participou da estruturação do artigo e fez as revisôes do conteúdo. 


\section{Abstract}

\section{The claim of freedom: deinstitutionalization movement and practices in the 1990s, through their posters}

This article aims to understand how the voices that changed the practices and ideas about madness organized their discourse and disputed meanings in the public space, through the analysis of advertising material for the Brazilian Psychiatric Reform. More specifically in 1990's posters, one of the social-historical and discursive moments focused in the thesis: "Social Movements in Health and Strategies of Production of Senses: in the claim of freedom, the new place of madness". The posters were analyzed in their discourses trying to identify, comprehend and compare the enunciation devices in the light of their temporal and geographical aspects. The results identify the 1990's as a moment of consolidation for deinstitutionalization movement and practices (anti-manicomial), when culture, freedom and citizenship were the main values, which built the meaning of that historical moment.

Keywords: Communication and Health; movement and deinstitutionalization practices; discourse analysis. 